\title{
A Comparative Study Installation Arrangement of Primary Flight Display (PFD) in the Flight Deck's Regional Passenger Transport Aircraft
}

\author{
Anantia Prakasa $^{1 *)}$, Indra Permana Sophian ${ }^{2)}$ \\ 1) Prodi Teknik Telekomunikasi, Fakultas Teknik Elektro dan Telekomunikasi (FTTE), \\ Institut Teknologi Telkom Purwokerto (ITTP), Purwokerto \\ 2) PT Regio Aviasi Indonesia (PT RAI), \\ Flight System Directorate, Flight Deck Department, Bandung \\ * email: anantia@ittelkom-pwt.ac.id
}

\begin{abstract}
The Flight Deck or cockpit is designed to support the prosecution of its aircraft mission and these are what the Flight Deck design process needs to ensure but not limited to display design, aircraft control, automation, HCI on the Flight Deck and pilot's view to outside namely external vision. The external vision must satisfy regulatory requirements which intended to ensure that the view is adequate for pilots to operate the aircraft safely and gives them a reasonable opportunity to see and avoid other aircraft that pose a collision threat. Concurrently during critical periods of flight, it is important that the flight crew access information in front of his view with minimal head rotation. Cockpit-Displays with critical flight information should then be located to these locations. Compromising both external and internal vision as Pilot's visibility should be attained. Further, some OPTIONs to arrange the $P F D$ in cockpit instrument panel give difficulty in term of its panel space, safety and comfort for the pilots. Two layout PFD's, In-line and T-line layout, are evaluated in the new Regional Aircraft Cockpit using avionics 15.1" or 14.1" display. Due to cockpit space, the In-Line four of 15.1" display cannot fit the instrument panel and disregard; however the T-Line for 15.1" display is possible as OPTION 1. The four of 14.1" displays are possible to arrange as InLine and T-Line layout as OPTION 2 and OPTION 3 respectively, and both may offer compliance to regulatory requirements also to both Pilot's external and internal vision.
\end{abstract}

Keywords - Flight Deck/Cockpit, Primary Flight Display (PFD), regulatory requirements, flight crew's external / internal vision, pilot visibility

\section{Introduction}

The similar name for aircraft's flight deck is cockpit or pilot compartment. The spatial arrangement and the physical ergonomics of a flight deck, including the location and design of the display system, begins at Eye Reference Point (ERP). From this design eye position (DEP), external and internal vision, seat geometry and the arrangement of controls is all determined. The importance of both external and internal vision is also related to Pilot task, e.g.: hand/footeye coordination for landing or take-offs [1]. Furthermore pilot's external vision have function for situational awareness; failure of shortage Pilot's external vision might be bring incident or even accident. For example, the incidents that suspect to shortage of Pilot's external vision are such two Indonesian planes touched wings on the runway at the Kualanamu Airport Medan, also Virgin Atlantic struck by an Egypt Air awaiting take off [2][3]. Method to develop flight deck have already discuss in [4] avowed as aviation industry standard, and as material guidance seen in [5] also summarized in [6] as preferences to develop flight deck.

The purpose of this paper is to present the study installation arrantgement of Primary Flight Display (PFD) in the new PT RAI Regional Aircraft Cockpit panel as a Pilot's instrument. The PFD installations can be arrange in various layout such T-line-layout or InLine-layout which compromise to available space in flight deck, also the installation will

Manuscript submitted 22 August 2019; revised 29 August 2019; accepted 30 August 2019.

Published 31 August 2019; http://dx.doi.org/10.28989/avitec.v1i1.505 
consider to Pilot's external vision and Pilot's internal vision.

Further, an research questions will also address the suitable 15.1" and 14.1" cockpit's flight display size comfort for pilots in flight deck with available cockpit geometry by remembering mandatory flight-information for both pilots would be visible in each pilot's station.

\section{Methodology}

The methodology considered to place the PFD in the cockpit instrument panel are refer to FAA regulations as follows:

1. External Vision as per FAA AC 25.773-1 [7]

2. Internal Vision as recommend as per FAA AC 25.11-B [8], AC 1322-1 Appendix 5 [9], GAMA Publication 10 Section 4 [10].

Both external vision and internal vision set the same DEP (Design Eye Point) defined as "position at each Pilot's station from a seated pilot achieves the required combination of outside visibility and instrument scan. It is normally a point fixed at which the midpoint of the pilot's eyes should be located when seated at the normal position".

The initial DEP location when Pilot seated in his station are set shown on table 1.

Table 1. Design Eye Reference Point (DEP)

\begin{tabular}{l|l|l|l}
\hline \multirow{2}{*}{ CREW } & \multicolumn{3}{|c}{ COORDINATE } \\
\cline { 2 - 4 } & $\mathrm{X}$ & \multicolumn{1}{|c}{$\mathrm{Y}$} & $\mathrm{Z}$ \\
\hline Pilot & 3150 & -512 & 4172 \\
\hline Co-pilot & 3150 & 512 & 4172 \\
\hline
\end{tabular}

The reference point of both initial and modify DEP are to the projection of edge of nose radome of the aircraft in the ground.

\subsection{External Vision}

The regulations FAA AC 25.773-1 [7] straighten up the minimum Pilot's external vision from the flight deck. The external vision analysis is measured using "polar projection", which are angle-angle plots of the limits of the solid angle that the pilots can see out the windows.

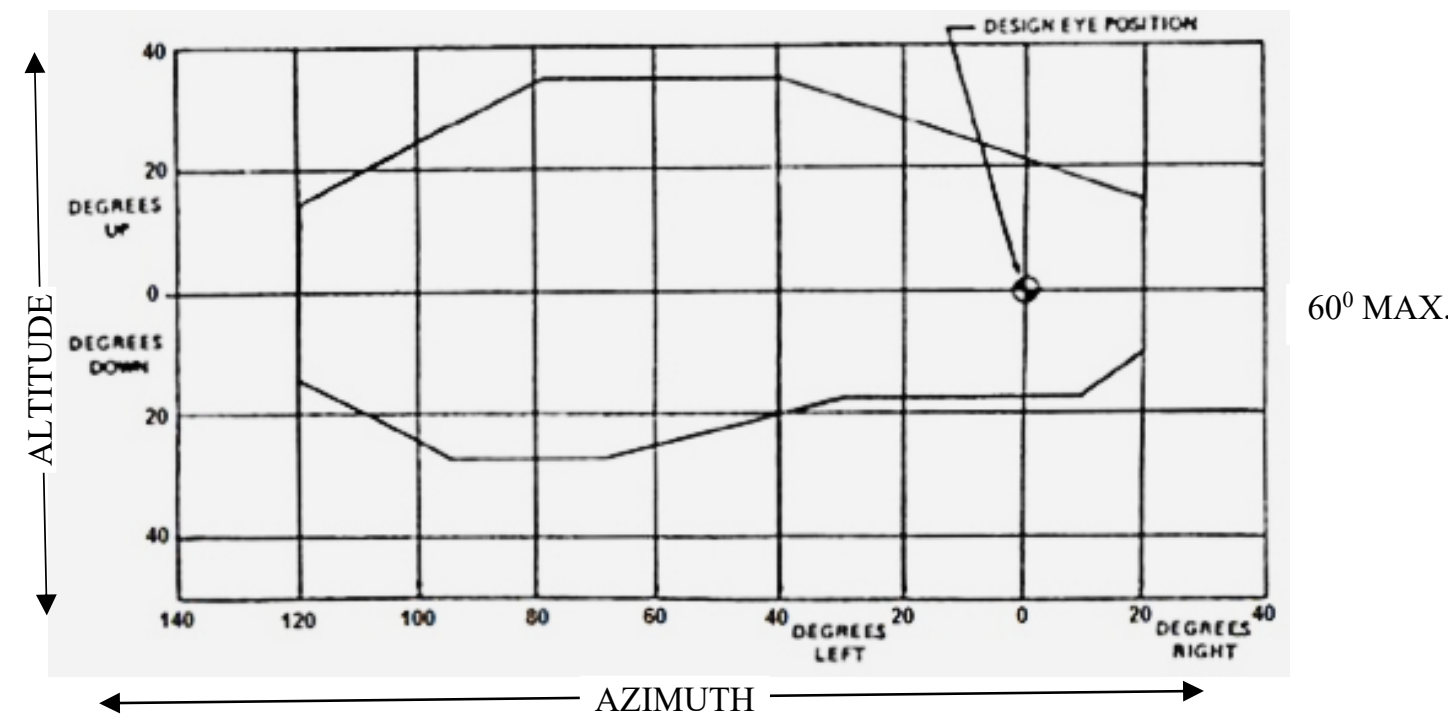

Figure 1. FAA AC 25.773-1 regulatory requirements for pilot external vision [7]. 
The polar projection is a two dimensional curve that specifies combinations of left/right angles (azimuth) and up/down angles (altitude) measured from the line straight forward from the Pilot's eyes. Those azimuth and altitude combinations represent the limits of the pilot's field of view out the windows. The current cockpit-front-window designed is measured by comparing the polar projection of current window againts the polar projection of regulatory requirements above, expressed in angle/angle coordinates.

\subsection{Internal Vision}

The internal vision is measured by vision cone concept. The vision cone theory is illustrated in figure 2. Cone A and cone B in figure 2 shows the possible radius human's eyes vision to see an object without difficulty.

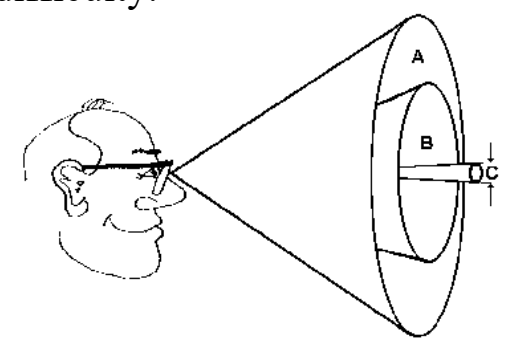

Figure 2. Vision Cone.

The limits of vision associated with eye motion only are referred to as the primary vision cone which associated to cone $\mathrm{B}$, while the limits are refered to head motion are known as the secondary vision cone which associated to cone A.
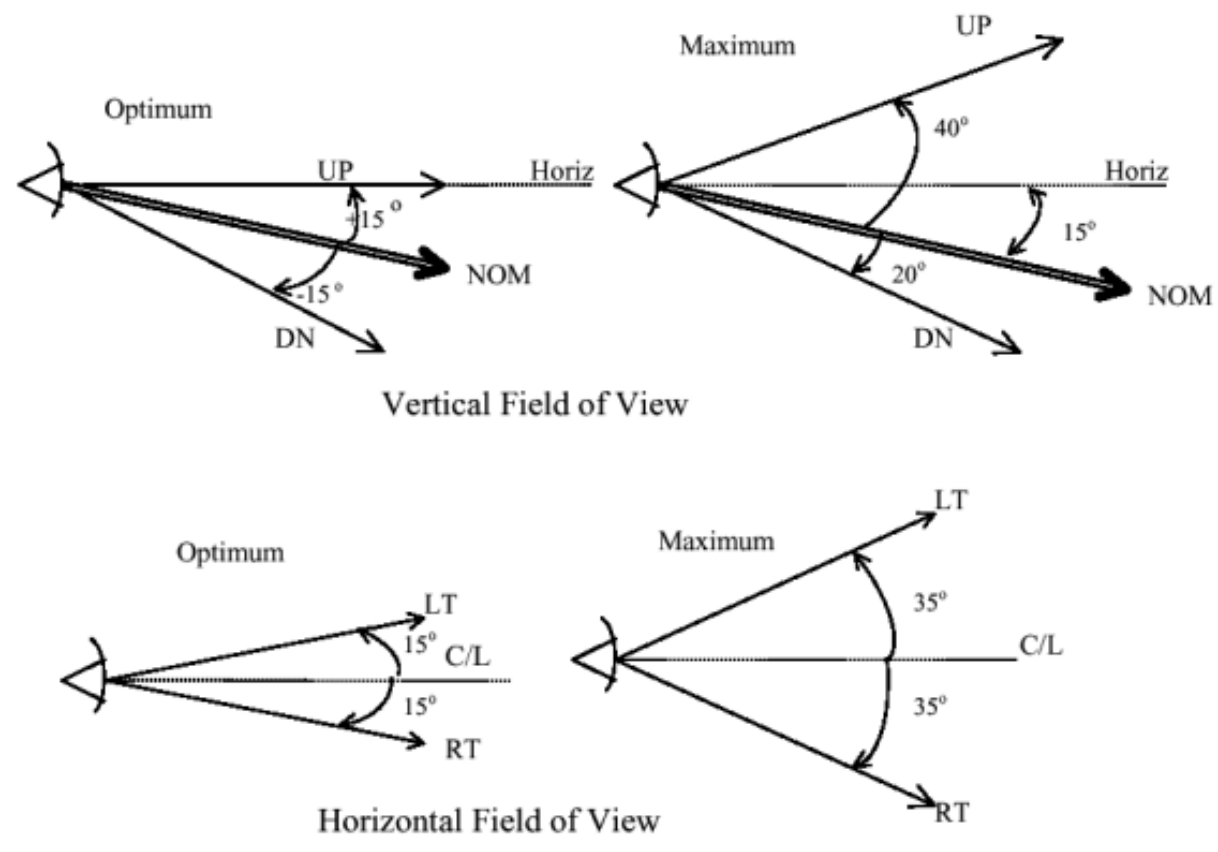

Figure 3. Primary Field of View (FOV) - Vertical and Horizontal.

The primary vision cone is defined as region with 15 degrees radius extending from the normal line of sight (NOM), the normal line of sight (NOM) is established as 15 degrees below a line extending horizontally from the eye. These values are established from the normal line of sight and depicted in figure 3. 
The secondary vision cone is based upon the maximum horizontal and vertical visual fields from the design eye reference point that can be accommodated with head rotation. These values are $+/-60$ degrees horizontal and +65 and -35 degrees vertical. These values are established from the Center Line $(\mathrm{C} / \mathrm{L})$ and normal line of sight respectively and depicted in figure 4 .

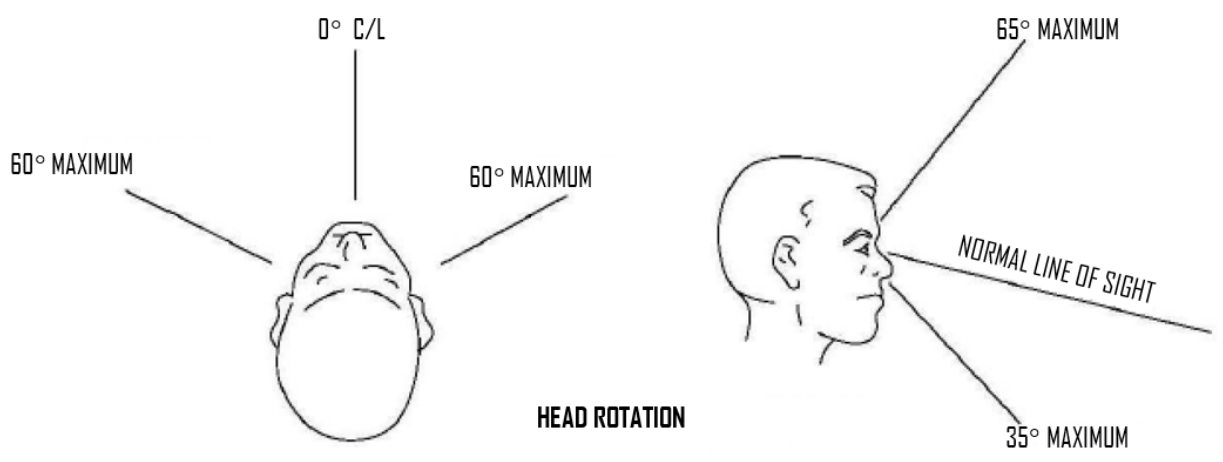

Figure 4. Secondary Field of View (FOV).

The evaluation of internal vision is done by superimpose primary and secondary FOV as "Total Field of View (FOV)" with respect to DEP, that can be accommodated with eyes rotation.

The figure 5 depict an example of total primary FOV of pilot's visual cone when he/she sits in the cockpit in normal position; follow by figure 6 depict an example of total secondary FOV of pilot's visual cone in same position.

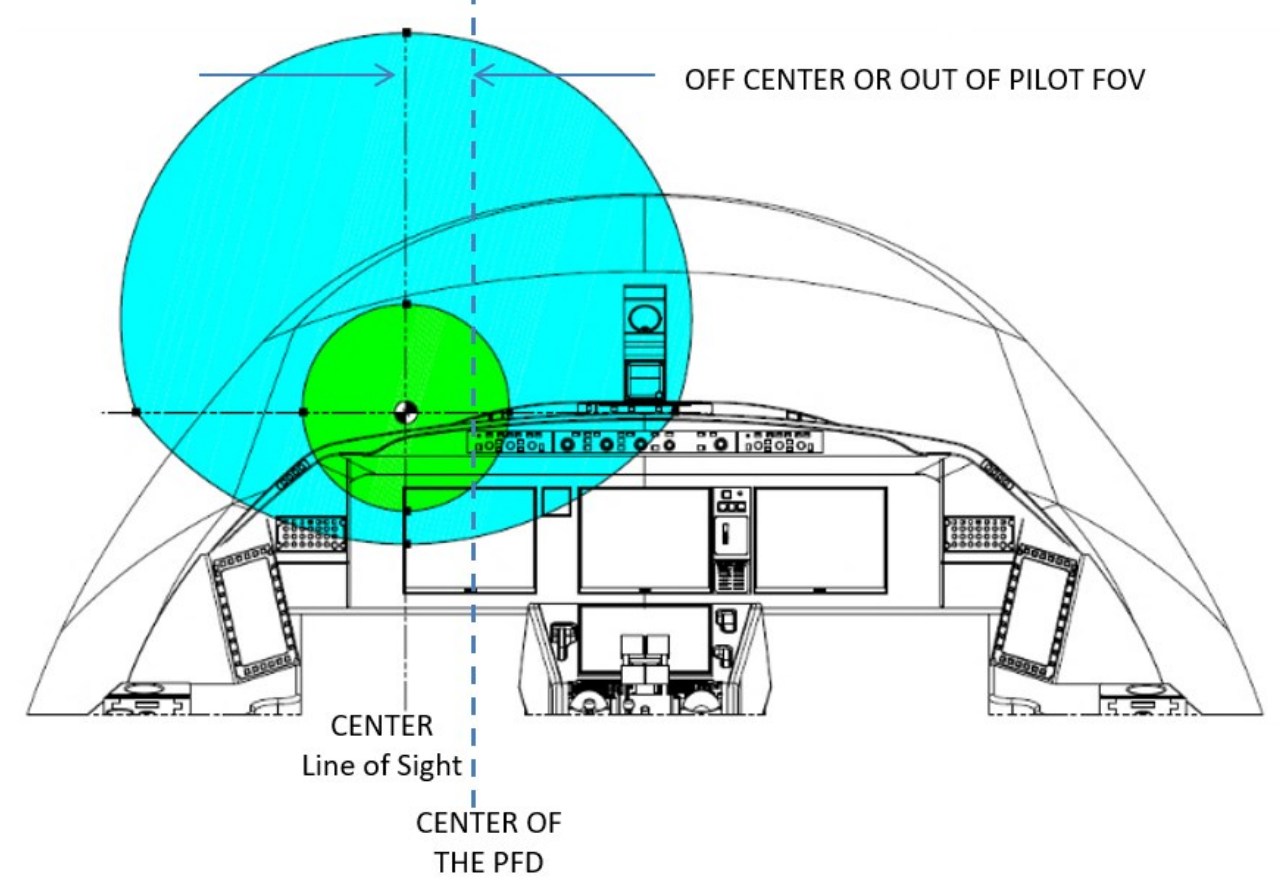

Figure 5. Total Primary FOV of Pilot's internal Vision

Both figure 5 and 6 use same DEP location; and particularly from figure 5 it is shown the cockpit PFD located Off-Center or Out-of Pilot NOM (normal line of sight). Locating the PFD Off-Center can cause the pilot to adopt uncomfortable or awkward positions, in which leading to pain. So we should put the DEP wherever possible come closer or in the PFDvertical-line-center 


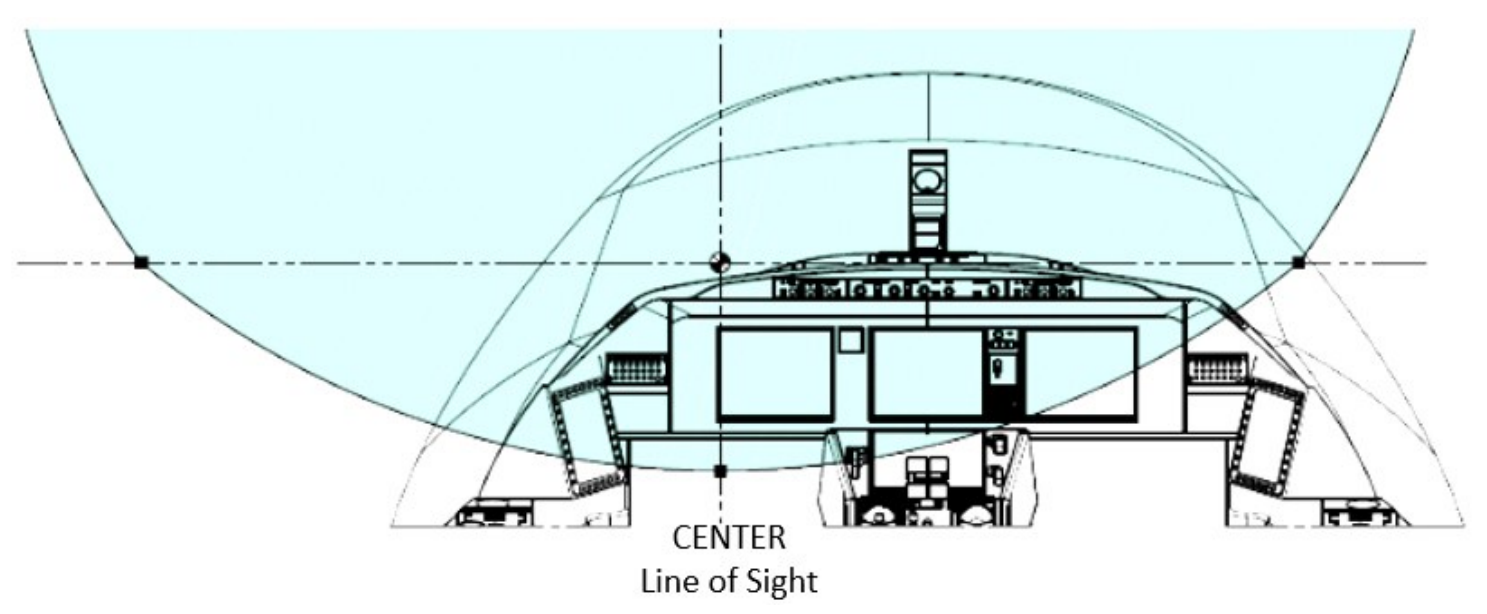

Figure 6. Total Secondary FOV of Pilot;s internal Vision.

The following are material sourcing of definition Primary FOV and Secondary FOV above.

1. The DOT/FAA/TC-16/56 table 2.3-1 [11] mention the terminology such the Primary FOV, Primary Optimum FOV, Primary Maximum FOV from source material such as FAA AC.

a. The FAA AC 25-11B Appendix C.74 [8] mentions the terminology Primary Maximum FOV as depicted in figure 3; which show the Primary FOV is based on the optimum vertical and horizontal visual fields from the design eye reference point that can be viewed with eye rotation only using foveal or central vision. With the normal line of sight established at 15 degrees below the horizontal plane, the values for the vertical (relative to normal line of sight forward to aircraft) are $+/-15$ degrees optimum, with +40 degrees up and -20 degrees down maximum. See figure 3.

b. FAA AC 25.1322-1 Appendix 5 [9] mentions the Primary FOV based upon the optimum vertical and horizontal visual fields from the design eye reference point that can be accommodated with eye rotation only. With the normal lineof-sight established at 15 degrees below the horizontal plane, the values for the vertical (relative to normal line-of-sight forward of the aircraft) are $+/-15$ degrees optimum, with +40 degrees up and -20 degrees down maximum. For the horizontal visual fields (relative to normal line-of-sight forward of the aircraft), the values are $+/-15$ degrees optimum, and +/- 35 degrees maximum. See figure 3.

2. The DOT/FAA/TC-16/56 table 2.3-2 [11] mention Optimum vertical and horizontal visual fields, Central visual field, FOV, Optimum visual zone, Primary FOV, Secondary FOV, Forward FOV from various research report and guidance documents.

a. Gama Publications No.10 mentions the Primary FOV and the Secondary FOV as follows: Secondary Field-of-View is based upon the optimum horizontal and vertical visual fields from the design eye reference point that can be accommodated with head rotation. These values are $+/-60$ degrees horizontal and +65 and -35 degrees vertical. These values are established from the normal line of sight and illustrated in figure 4. The Secondary Field-of-View range defines the ability of the pilot to observe the operation and to use the critical parameters of a system without inducing disorientation or undue body movement. 


\section{Input \& Output Analysis}

The Pilot's external vision shall establish the dimension of cockpit front-windows and side window's size. On the other side, election of suitable PFD size will also determine the amount of mandatory flight-information avail to the Pilot's eyes easily from each pilot station. The mandatory flight-information are Basic-T flight-information such state in FAA FAR 25.1303 (b) (speed, altitute, attitude and heading) [12][13]. Compromise Pilot's external vision and Pilot's internal vision is subject exploration of this paper.

The regulation which should compromise to to the Pilot's visibility, both external vision and internal vision, as such to comply with regulatory requirements but not limited to FAA FAR 25.773-1 and FAA AC 25.773-1 [7].

\subsection{Flight Deck Initial Geometry}

The aircraft flight deck's geometry initially defined by the aircraft-structure group as part of aircraft fuselage. It ussually shows the pre-empt curve/surface and volume which iterate several times to meet aircraft aero model. Then the result are some OPTIONs avail to us which need to configure such Flight Deck Windows, flat or curve its windows which related to openable windows or not, external visibility from both Pilot's and Co'Pilot's eyes when sit normally in in the cockpit.

Figures 7 and 8 show the initial geometry of the flight deck envelope such as space and volume for cockpit instruments panel, cockpit floor, cockpit windows, and cockpit passing through for cockpit door.

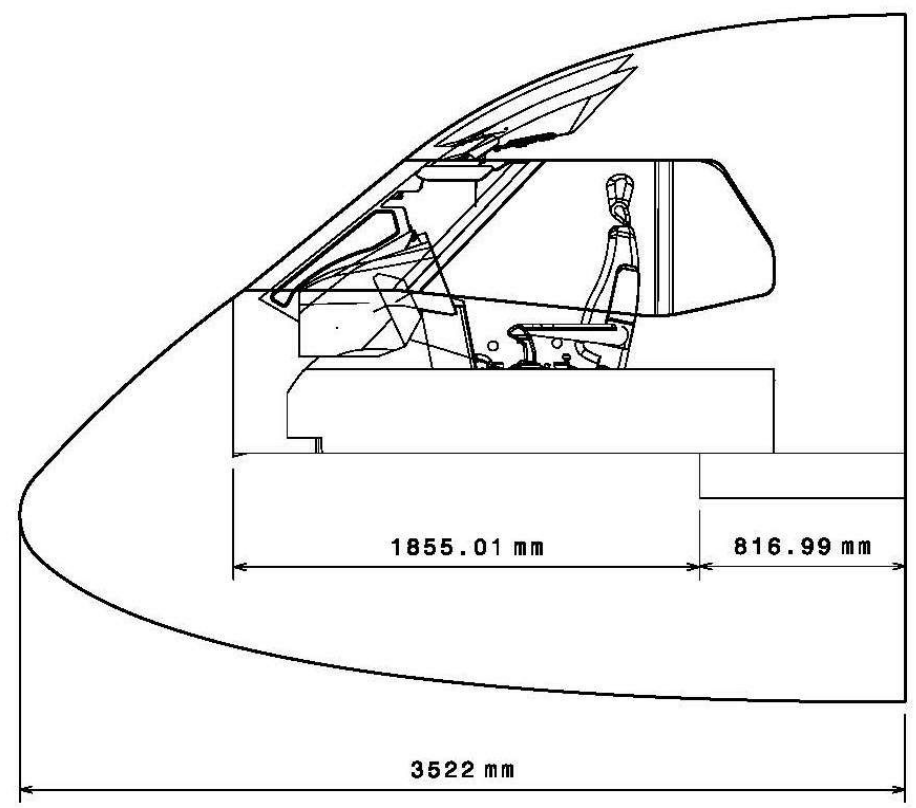

Figure 7. Flight Deck Initial Geometry - Side View. 


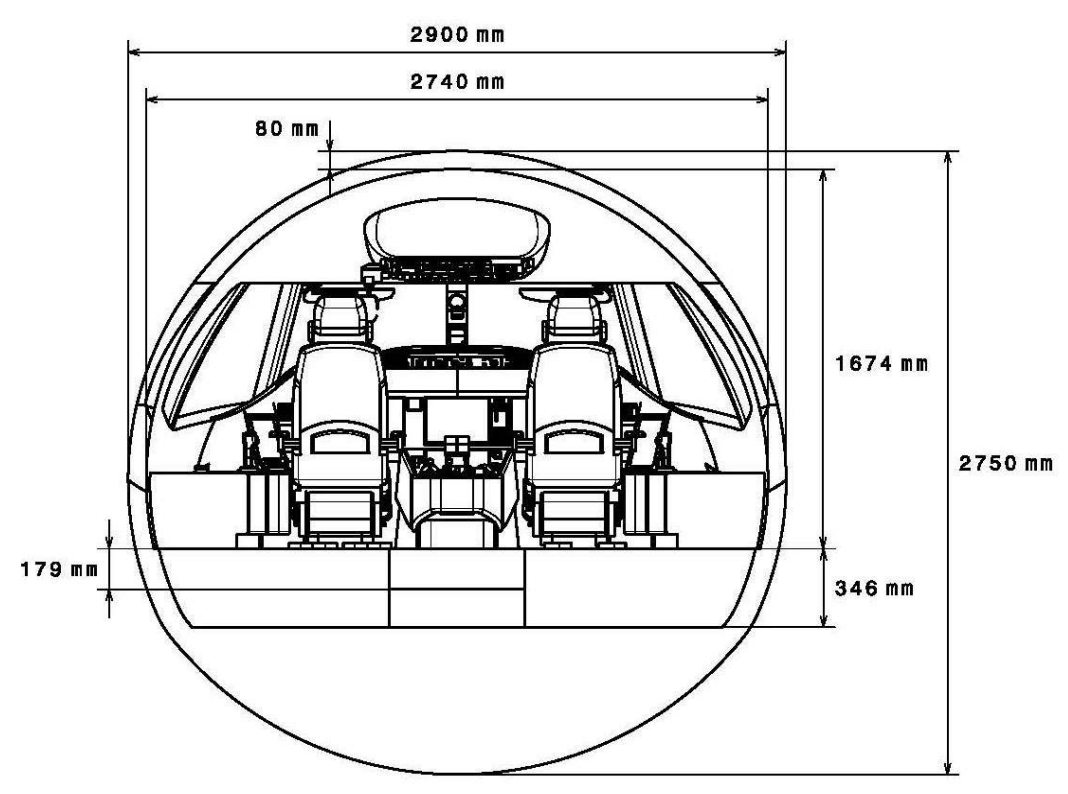

Figure 8. Flight Deck Initial Geometry - Aft View (continued).

\subsection{Avionics Cockpit Primary Flight Display (PFD)}

The table 2 shows the avail avionics PFD or flight-display with various size and capability. "Smart Display Type" means the "Graphic Symbol Generator Processor" and "Display Processor" are embedded in the display itself. The "Dumb Display", in the contrary" the display processor is separated from "Graphic Symbol generator processor". An example of dumb display is mostly display sed in the laptop.

Table 2 Avionics Cockpit PFD Dimension

\begin{tabular}{c|c|c|c|c}
\hline \multirow{2}{*}{ OPTIONs } & Display Type & \multicolumn{2}{|c|}{ Size } & \multirow{2}{*}{ Vendors } \\
\cline { 3 - 4 } & & Bezel (W, H) & Viewing (W, H) & \\
\hline 1 & Smart Display 15,1" & $13.41 "$ X 10.92" & $12.071 "$ X 9.053" & RC \\
\hline 2 & Smart Display 14.1" & $13.3^{\prime \prime}$ X 9.2" & & RC \\
\hline 3 & Dumb Display 14.1" & $12.35^{\prime \prime}$ X 9.98" & & Honeywell \\
\hline
\end{tabular}

The pros and cons between cockpit displays above in term of installation, operational and maintenance concern. Dumb display bargains easy in installation and maintenance including replacement the hardware itself, but give hassle integration in term of electronicsschematic. In different Smart Display offers aggrave installation and maintenance simultaneously give easy integration. Both display offer similar operational function however it is pilot's subjective.

\subsection{Input file}

There are two's thing input requirements: first thing as input file is "the initial Flight Deck Geometry" in figure 10 and 11 section 4.1 which depicts the dimension "outer" and "inner" aircraft airfrme. Based on the the initial Flight Deck Geometry, the cockpit windows size for Pilot's external vision can be estimated as shown on figure below.

The second things is "avionics PFD or flight-display dimension - in table 2" will be placed on the cockpit instrument panel and DEP as representation of Pilot's eyes. 


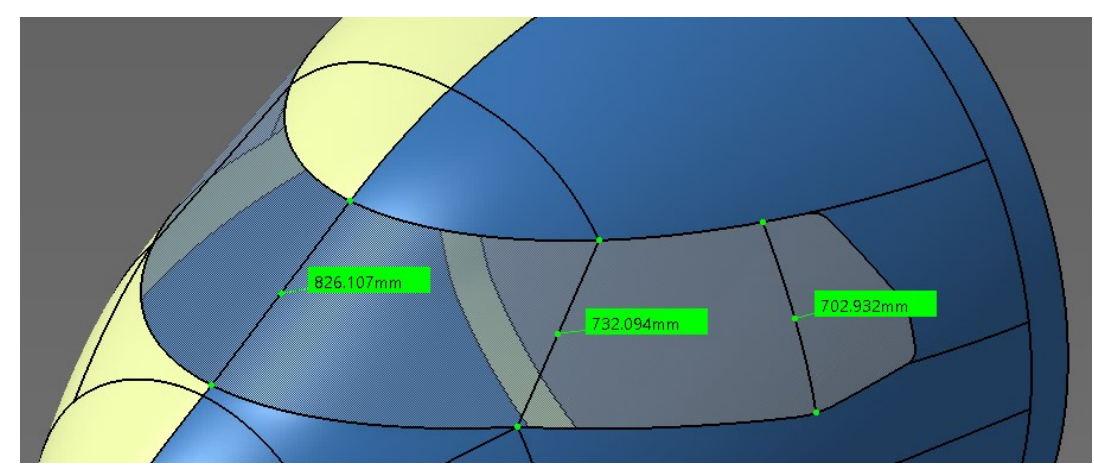

Figure 9. Flight Deck / Cockpit Windows Size based on Initial Flight Deck Geometry

Based on the figure 9 above the Pilot's external vision can be plotted and showed in figure 10. The figures 10 and 11 depict the Pilot's external vision from his seat position and there is obstructed vision from Pilot's DEP (Blue-line) and when it roll-up as two dimensional drawing: there is 5 degree portion less from desired AC 25.773-1 (Red-line). However, the external vision maybe satisfied which only left up portion of window more or less than 5 degree from desired requirements.

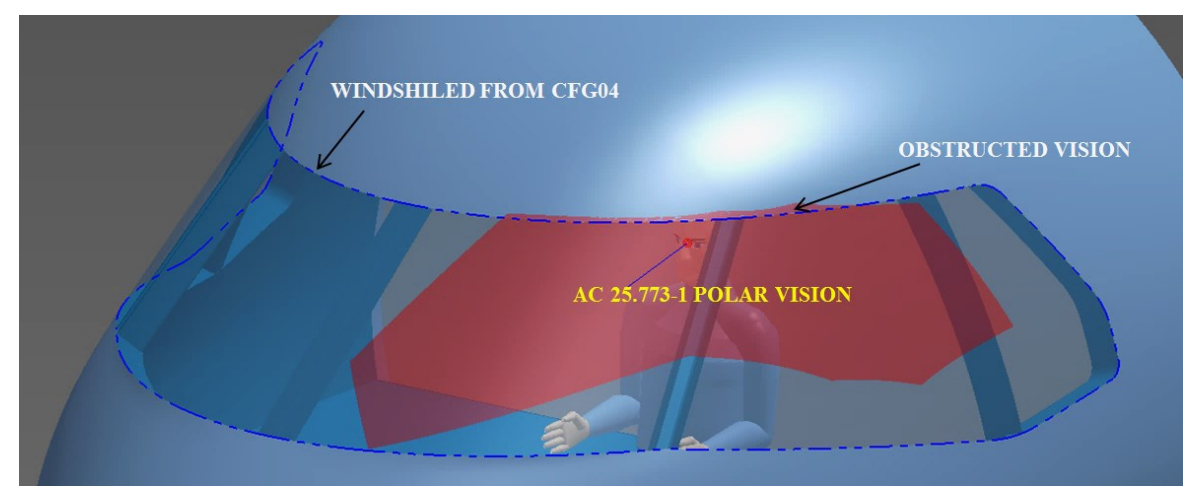

Figure 10. Plotted of Pilot's external vision into 2-D dimension

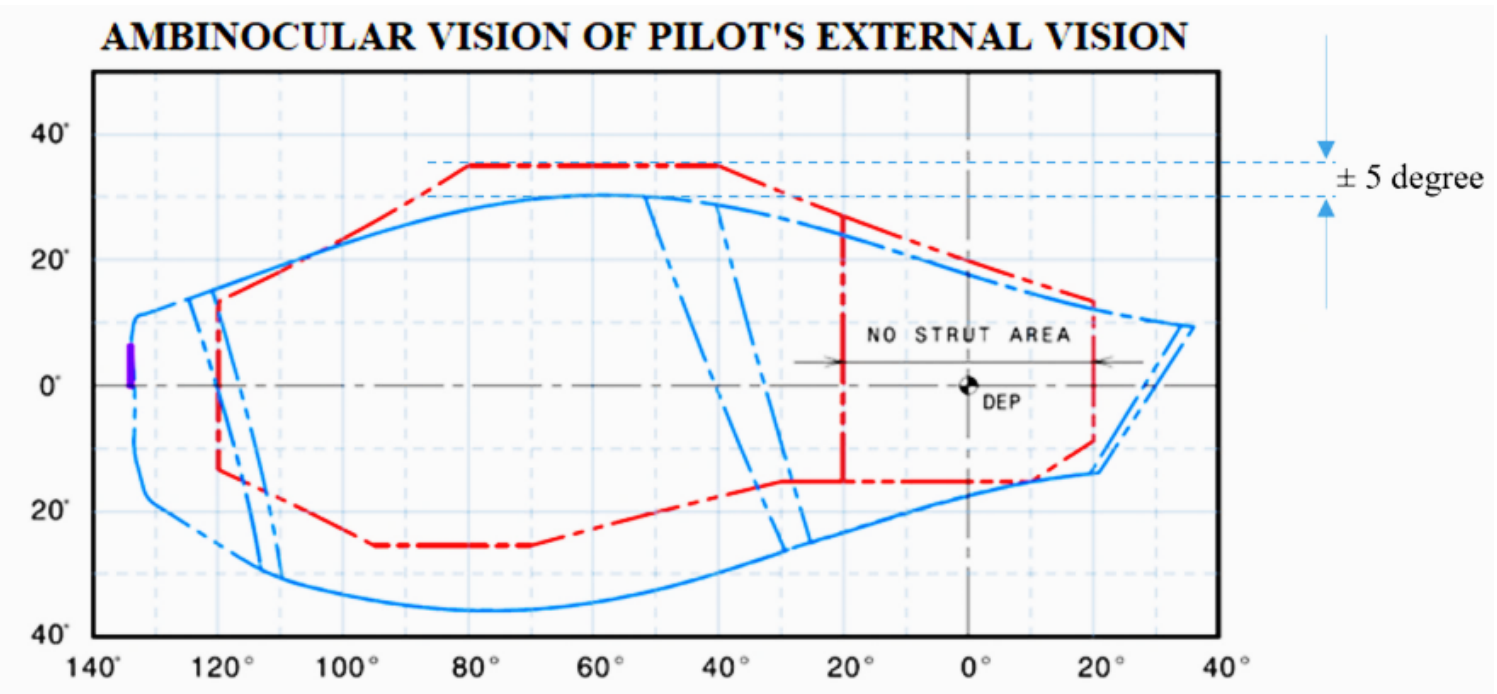

Figure 11. Plotted of Pilot's external vision into 2-D dimension 


\subsection{Output file and analysis}

Based on the initial Flight Deck Geometry, position of avionics PFD in the cockpitinstrument panel and both the Pilot's + CoPilot's DEP, we can analyse to obtain Pilot's external vision and internal vision showing on the figure in next section below. The several steps iteration such DEP relocation to meet simultaneously Pilot's external vision and internal vision onto the PFD in the cockpit panel are carried out.

\subsection{External Vision}

The figure 12 depict the Pilot's external vision from his seat position through outside. The OPTION 1 is related to Smart Display 15" PFD and DEP in table 1, OPTION 2 is related to Smart Display 14.1" PFD plus DEP in table 3, and the last OPTION 3 is related to Dumb Display 14.1 PFD respectively plus DEP in table 3.

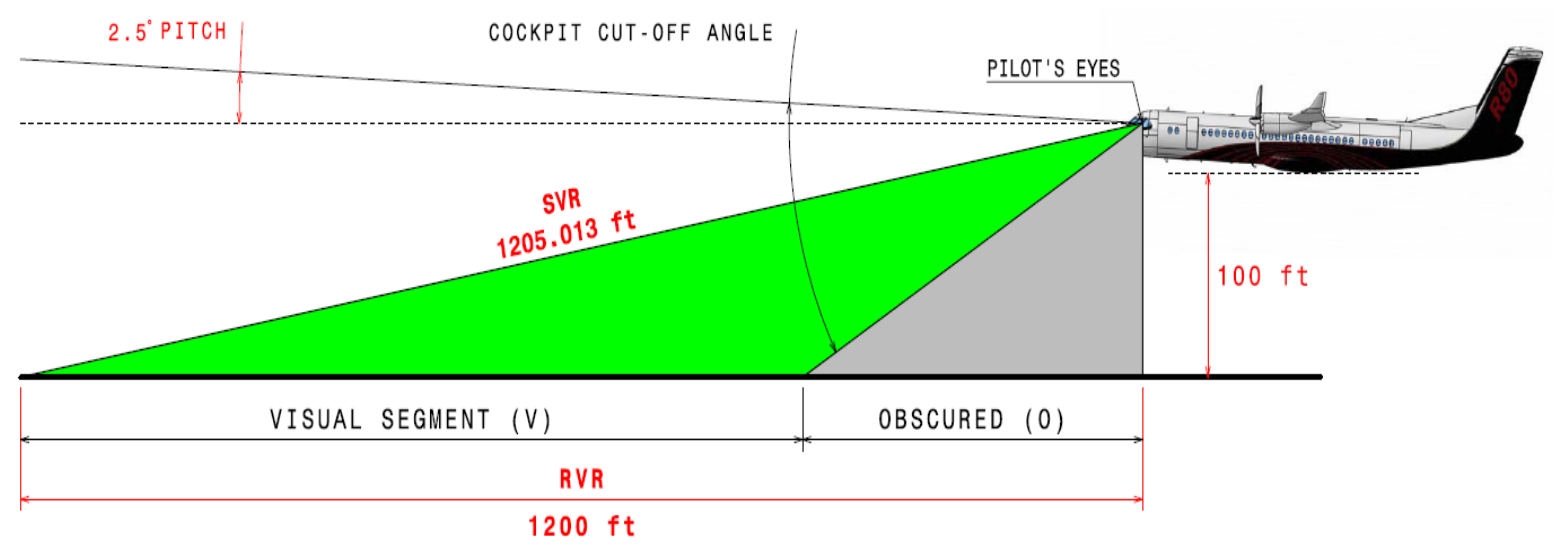

\begin{tabular}{|c|c|c|c|c|c|c|}
\hline \multirow{2}{*}{ DEP POSITION } & \multicolumn{2}{|c|}{ CURRENT WINDSHIELD FROM CFG 04 } & \multicolumn{3}{c|}{ PROPOSED EXTERNAL VISIBILITY } \\
\cline { 2 - 7 } & $\mathbf{V}(\mathbf{f t})$ & $\mathbf{0}(\mathbf{f t})$ & $\begin{array}{c}\text { COKCPIT CUT- } \\
\text { OFF ANGLE } \\
\text { (deg) }\end{array}$ & $\mathbf{V}(\mathbf{f t})$ & $\mathbf{0}(\mathbf{f t})$ & $\begin{array}{c}\text { COKCPIT CUT- } \\
\text { OFF ANGLE } \\
\text { (deg) }\end{array}$ \\
\hline OPTION 1 & 822.193 & 377.807 & 18.701 & 827.395 & 372.605 & 18.915 \\
\hline OPTION 2 & 823.734 & 376.266 & 18.769 & 828.841 & 371.159 & 18.98 \\
\hline OPTION 3 & 835.197 & 364.803 & 19.247 & 840.235 & 359.765 & 19.468 \\
\hline
\end{tabular}

Figure 12. Landing Vision for 3 (three) OPTIONs

\subsection{Internal Vision}

To analyze the Pilot's internal vision, three kind of avionics PFD's as seen table 2 are compared during placed in cockpit panel instruments. After the PFD install, we measure the Pilot's internal vision to cope the information on the display. First trial by used 15.1" display and the result shown on below.

\subsubsection{Horizontal Field of View (FOV): Primary and Secondary}

By applying the internal vision horizontally such mention in sect. 3.2 (Figures 3 and 4) then Figures 13 and 14 come by the Horizontal FOV Primary and Secondary respectively.

The green-band shows the Optimum Pilot FOV and the Blue-Band shows the Maximum Pilot FOV. The red-line represents the position of center-line of Instrument panel. 


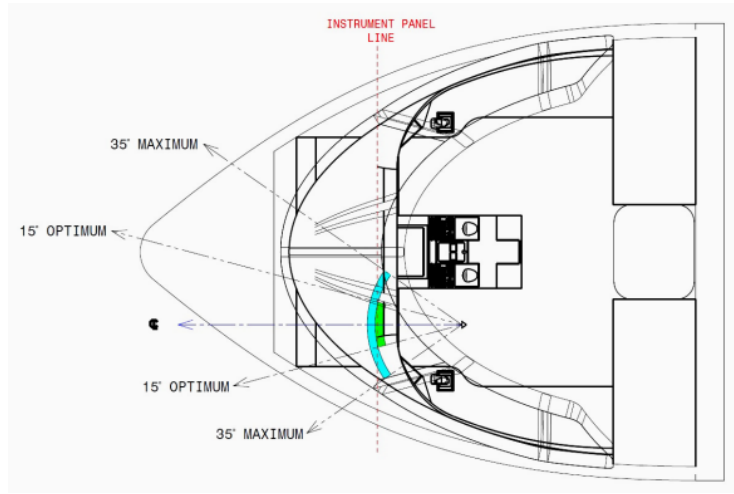

Figure 13. Horizontal Primary FOV

Approximately the display-instrument and display-controller is arranged for use by any pilot and readily visible to the pilot, and the display-location, with respect to the pilot's eye (DEP) fully readable up to horizontal viewing angle of 35 degrees from normal to the face of the display screen.

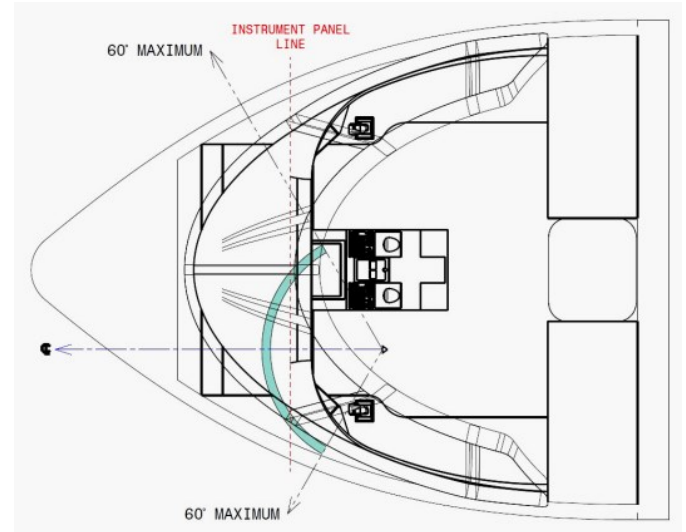

Figure 14. Horizontal Secondary FOV

At glance, the size of the viewing envelope will provide visibility of the flight deck displays over the flight-crew's normal range of head of motion, and support cross flight deck viewing when necessary.

\subsubsection{Vertical Field Of View (FOV): Primary and Secondary}

Further, applying internal vision vertically mention in sect. 3.2 (Figure $3 \& 4$ ) then Figure 15 and 16 come by the Vertical FOV Primary and Secondary respectively.

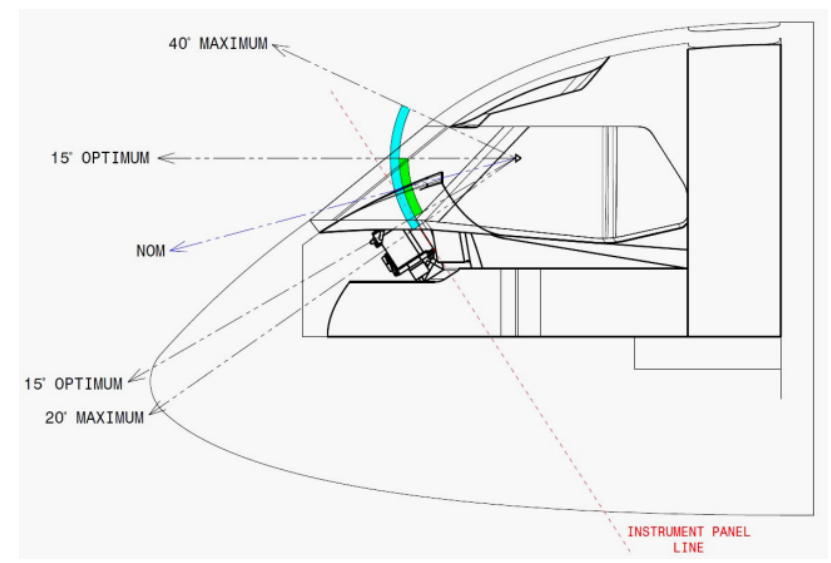

Figure 15. Vertical Primary FOV 
At glance, the internal visibility covers vertically the upper portion through the instrument panel and lower portion of the cockpit. The figure 17 below shows the Primary Vertical FOV where the green-bands show the Optimum Vertical-Pilot's FOV and blue-band shows Maximum Vertical-Pilot's FOV. The red-line represents the position of Instrument panel. Figure 16 shows proposed secondary vertical FOV where grey-band indicated secondary vertical-Pilot's FOV.

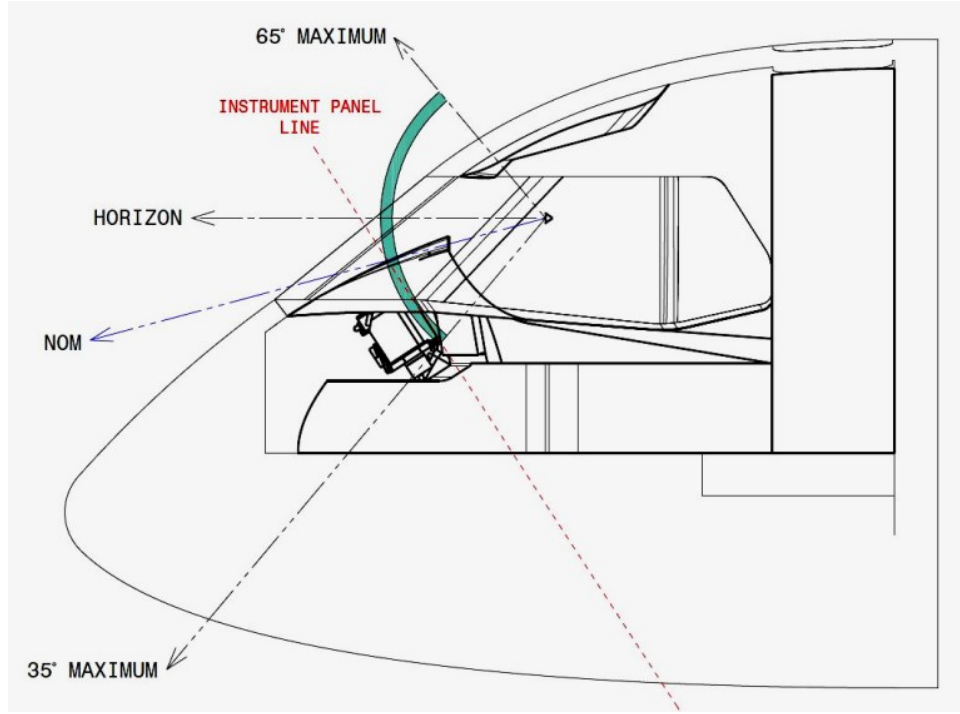

Figure 16. Vertical Secondary FOV

\subsubsection{Total Field of View (FOV): Primary and Secondary}

Total Primary FOV figure 17 is summation of the Horizontal Primary FOV (Figure 13) and Vertical Primary FOV (Figure 15) with respect to DEP-Table 3 that can be accommodated with Pilot's eyes rotation for 15.1" display depict in Figure 17.
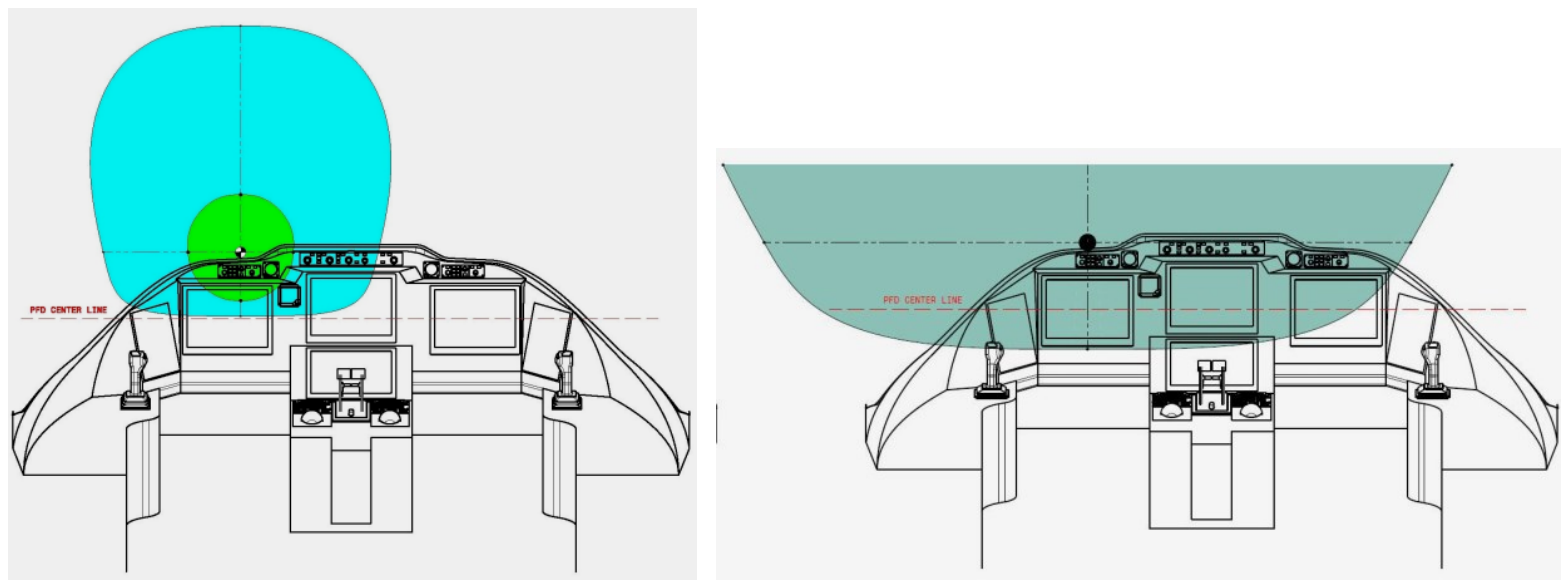

Figure 17. Total Primary FOV - Left and Total Secondary - Right (OPTION 1)

Similarly, the Total Secondary FOV is based upon the Horizontal Secondary FOV (Figure 14) and Vertical Secondary FOV (Figure 16) with respect to DEP-Table 3 that can be accommodated with head rotation. 


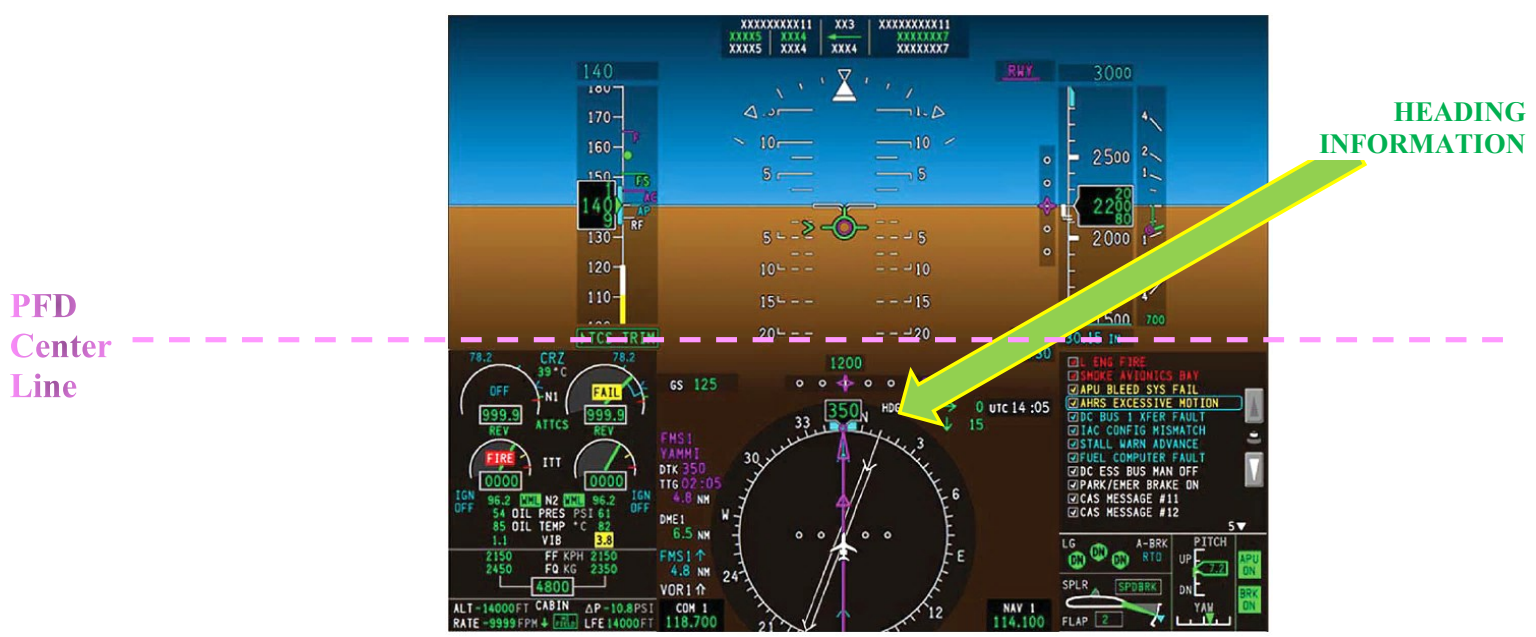

Figure 18. RC 15.1" PFD - Heading Information below the center line \& out of Primary FOV

3.7 Result Analysis Pilot's internal vision of various Primary Flight Display (PFD)

It concludes analyses based on figures above as follows:

1. The avionics PFD 15.1" with T-line layout arrangement, shown on figure 17 and 18, might not satisfy due to out-of-view the "Heading information" depict in Figure 18 by Pilot's scan-view. For this reason another 14.1" PFD layout arrangement are considered below.

2. The 15.1" PFD In-Line Layout is not considered due to unavailable space in cockpit compromising simultaneously external vision and internal vision.

3. Other OPTIONs to use 14.1" PFD required Pilot DEP to relocate to new coordinat.

Table 3. Proposed relocation of Design Eye Reference Point (DEP) for 14.1” PFD

\begin{tabular}{l|l|l|l}
\hline \multirow{2}{*}{ CREW } & \multicolumn{3}{|c}{ COORDINATE } \\
\cline { 2 - 4 } & $\mathrm{X}$ & \multicolumn{1}{c}{$\mathrm{Y}$} & $\mathrm{Z}$ \\
\hline Pilot & 3088.97 & -420 & 4160.01 \\
\hline Co-pilot & 3088.97 & 420 & 4160.01 \\
\hline
\end{tabular}

4. The avionics PFD 14.1" with In-Line layout arrangement, shown in Figure 19. At glance, there is possibility if both two 14.1" closest-displays may provide Basic-T information within Primary Pilot FOV as illustrate in Figure 20 below.

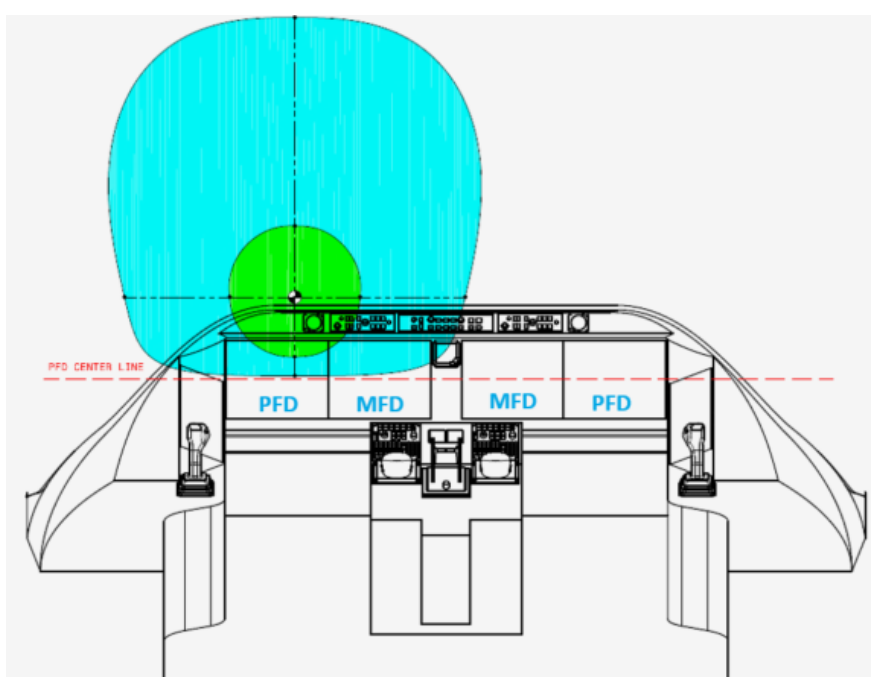

Figure 19. Total FOV of 14.1" PFD (OPTION 2) 


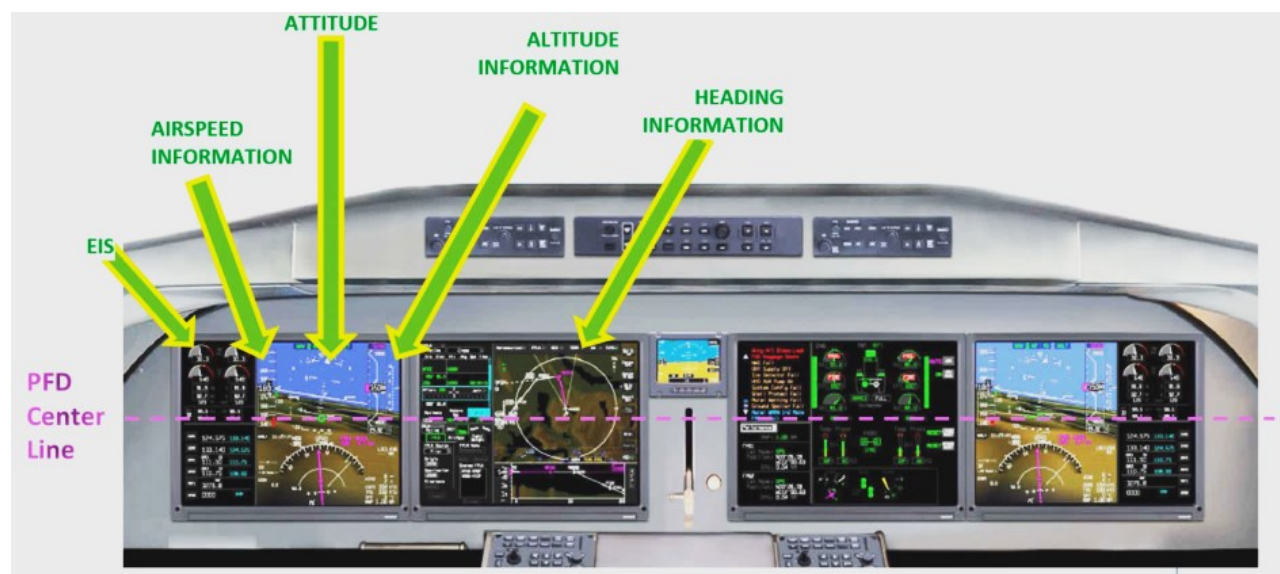

Figure 20. In-Line 14.1" PFD (OPTION 2)

5. Total Primary FOV in Figure 21 is internal vision resultant on the Horizontal Primary FOV and Vertical Primary FOV with respect to the OPTION 3. It indicates Vertical FOV may reach more than half portion of PFD such shown in Figure 22.

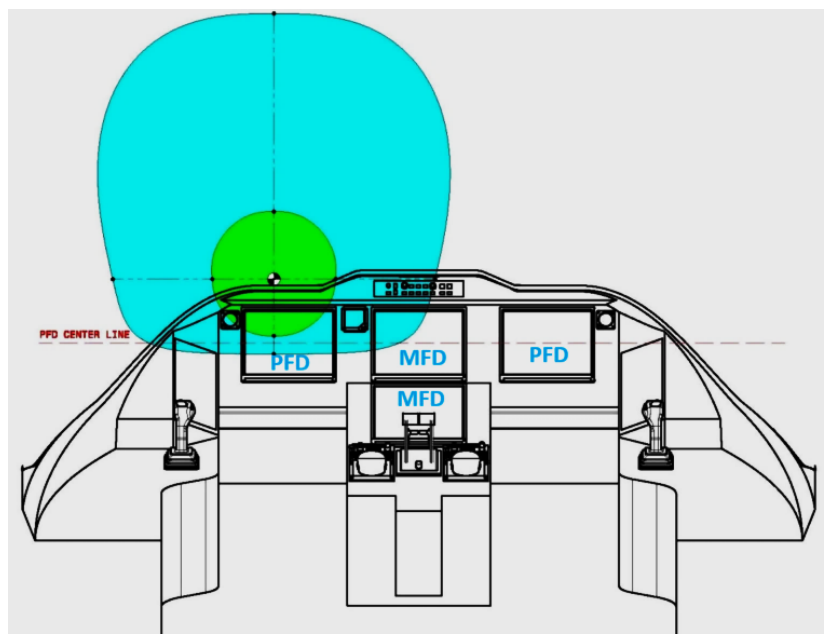

Figure 21. Total FOV of 14.1" PFD T-Layout (OPTION 3)

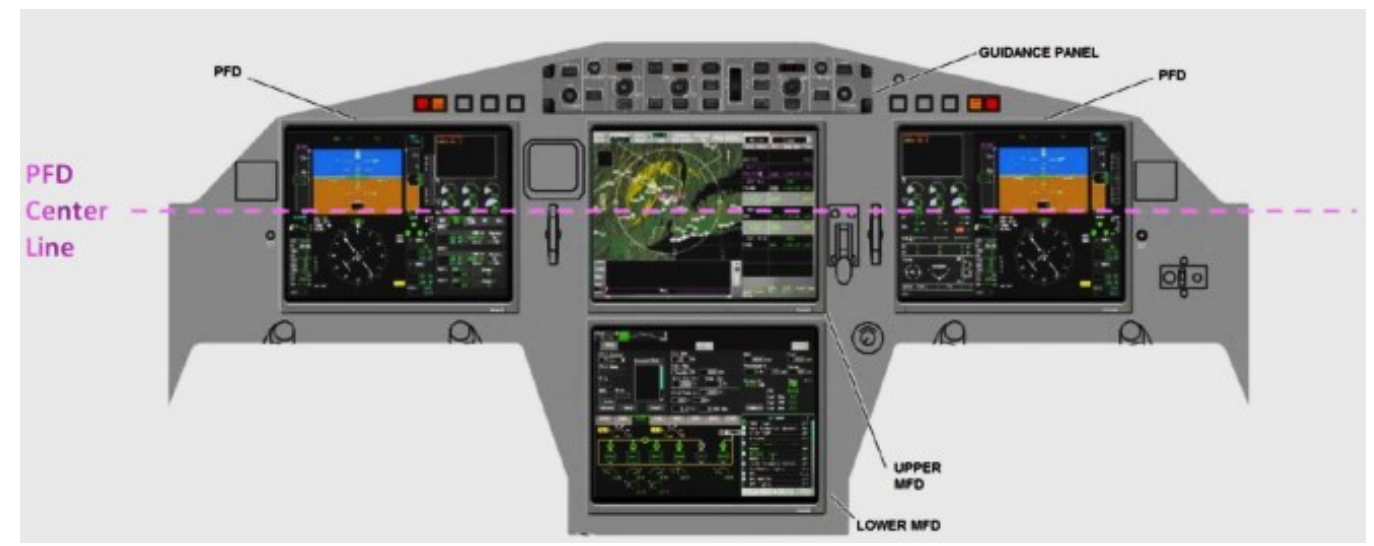

Figure 22 T-Line 14.1” PFD (OPTION 3)

\section{Conclusion and Notes}

During evaluation the positions avionics PFD in the cockpit instrument panel, it is found the DEP needed to relocate to meet the Pilot's internal vision and Pilot's external vision. 
Afterwards, we can analyse which the avionics PFD layout in the cockpit instrument panel meet the regulations AC 25.773-1 (external vision) and AC 25-11B, AC 1322-1 App.5 (internal vision). The following table shows pros and cons of PFD arrangements after evaluate.

Table 4. Pros and Cons PFD arrangement in Cockpit Instrument Panel

\begin{tabular}{c|c|l|l|l}
\hline OPT's & Display & \multicolumn{1}{c|}{ Pros } & \multicolumn{1}{c}{ Cons } & \multicolumn{1}{c}{ Notes (Vendor) } \\
\hline 1 & $15,1 "$ & $\begin{array}{l}\text { Provide more rich } \\
\text { information due to } \\
\text { avail screen size }\end{array}$ & $\begin{array}{l}\text { Flight Information } \\
\text { such Heading “out of } \\
\text { Primary FOV” }\end{array}$ & $\begin{array}{l}\text { It cannot be pursued to } \\
\text { evaluate due to } \\
\text { regulations }\end{array}$ \\
\hline 2 & $14.1 "$ & $\begin{array}{l}\text { Comply to } \\
\text { regulations }\end{array}$ & $\begin{array}{l}\text { Flight Information } \\
\text { within Primary FOV }\end{array}$ & Smart Display (RC) \\
\hline 3 & $14.1 "$ & $\begin{array}{l}\text { Comply to } \\
\text { regulations }\end{array}$ & $\begin{array}{l}\text { Flight Information } \\
\text { within Primary FOV }\end{array}$ & Dumb Display (HON) \\
\hline
\end{tabular}

\section{Acknowledgement}

The author are indebted to Avionics Group in PT Regio Aviasi Industri (PT RAI), for kindly offering invaluable insight and support during the production of this paper, particularly with regard to initial Flight Deck Geometry drawing and Flight Deck Group in PT Regio Aviasi Industri who comments the draft of this paper and corrected some drawing.

\section{References}

[1] S. Burgess, S. Boyd, and D. Boyd, "Fatal General Aviation Accidents in Furtherance of Business (1996-2015): Rates, Risk Factors, and Accident Causes," J. Aviat. Technol. Eng., vol. 8, no. 1, pp. 11-19, 2018.

[2] T. Don, "Egypt Air Boeing 777 to Cairo clipped the London-bound Virgin Atlantic flight Pictures taken by passengers show Virgin jet's wing tip being loaded onto truck," 2019.

[3] M. Penipuan and D. K. S. Radityo, "Kronologi Senggolan Lion Air dan Wings," vol. 23, pp. 2017-2020, 2017.

[4] Society of Automotive Engineer (SAE) Aerospace Recommended Practice (ARP), "SAE ARP 5056," ARP5056_Flight Deck Des. Process Part 25 Aircr., vol. 4970, 2006.

[5] M. Yeh, C. Swider, Y. J. Jo, and C. Donovan, "Human Factors Considerations in the Design and Evaluation of Flight Deck Displays and Controls Version 2.0," p. 396, 2016.

[6] Y. Zhang, Y. Sun, and Y. Chen, "A Framework for Ergonomics Design of Transport Category Airplane Cockpit,” Procedia Eng., vol. 80, pp. 573-580, 2014.

[7] Federal Aviation Administration, "Advisory Circular Advisory Circular AC 25.773-1," Advis. Circ., no. August, pp. 1-20, 2012.

[8] Federal Aviation Administration, "AC 25-11B Electronic Flight Display."

[9] Federal Aviation Administration, "Advisory Circular 25.1322-1: Flightcrew Alerting," Fed. Aviat. Adm., pp. 1-42, 2010.

[10] G. P. No, "Recommended Practices and Guidelines for Part 23 Cockpit / Flight Deck Design," no. 10.

[11] M. Yeh, Y. J. Jo, C. Donovan, S. Gabree, J. A. Volpe, and N. Transportation, "Human Factors Considerations in the Design and Evaluation of Flight Deck Displays and Controls," 2013.

[12] Federal Aviation Administration, "Aviation Circular Approval of Flight Guidance Systems," Aviat. Circ. Approv. Flight Guid. Syst., pp. 1-120, 2016.

[13] L. L. Lowry, "Federal Aviation Administration," SAGE Int. Encycl. Travel Tour., pp. 505-506, 2017. 